\title{
Efectos de la masificación turística y de los cambios en el consumo sobre los mercados locales. El caso de La Boquería de Barcelona.
}

\author{
Óscar Gutiérrez-Aragón* Eduard Alcaraz-Espriu** \\ Marta Solano-Tatché**** \\ Escuela Universitaria Mediterrani (España)
}

\begin{abstract}
Resumen: Los mercados locales de las ciudades se encuentran cada vez más amenazados por los nuevos tipos de comercio y establecimientos de venta. Además, también las tendencias de consumo han evolucionado, por lo que estos mercados deben ser capaces de adaptarse para sobrevivir. El principal objetivo de este trabajo es esclarecer el grado de influencia del auge del turismo como causa de la pérdida de público local en el Mercado de La Boquería, además de explorar las posibles mejoras para recuperar la clientela local. En la investigación se han utilizado metodologías de tipo cuantitativo (a partir de encuestas) y cualitativo (entrevistas a expertos y grupos de interés, herramienta UsabilityHub). Se concluye que el turismo es un factor determinante para la actual Boquería y habrá que tenerlo en cuenta para adaptarse a los nuevos tiempos y escenarios, sin dejar de seguir ofreciendo la mejor calidad, que siempre ha caracterizado el mercado.
\end{abstract}

Palabras Clave: Mercados locales; Tendencias de consumo; Turismo de masas; Gentrificación; Sostenibilidad.

Effects of tourist overcrowding and changes in consumption on local markets. The case of La Boqueria in Barcelona.

Abstract: Local city markets are increasingly threatened by new types of commerce and commercial establishments. Consumption trends have also been evolving, so these markets must be able to adapt to these changes if they want to survive. The main objective of this work is to clarify the degree of influence of tourism on the loss of local public in La Boquería Market, exploring the possible improvements to be made in order to try to recover the city clientele. The research used quantitative (from surveys) and qualitative methodologies (interviews with experts and interest groups, the UsabilityHub tool). It is concluded that, since tourism is currently a determining factor for La Boquería, it will have to be factored in when adapting to the new times and scenarios, always offering the best in quality that has been the hallmark feature of the market.

Keywords: Local markets; Consumption trends; Mass tourism; Gentrification; Sustainability.

\section{Introducción}

Los cambios en las tendencias de consumo, a medida que se modifican el conjunto de usos y costumbres y se adaptan a los estándares contemporáneos, son constantes y en muchas ocasiones tienen efectos evidentes y notables en la sociedad (Medina-Liberty, 2009; Gracia y Huertas-García, 2016; Martínez-Martínez, 2018). En este contexto, la aparición de supermercados e hipermercados y la consolidación de su popularidad como establecimientos comerciales de uso más habitual en ambientes urbanos y puntos clave en la compra de alimentos (Espinosa-Seguí, 2009; Huitink et al., 2020), además del auge del comercio electrónico en todos los ámbitos (Coronas, 2019; Serrano, 2020), impone a los mercados locales no sólo asumir un proceso de adaptación y de redirección hacia los canales que pueden

\footnotetext{
* Escuela Universitaria Mediterrani (España); E-mail: oscar.gutierrez@mediterrani.com; http://orcid.org/0000-0002-4417-6310 ** Escuela Universitaria Mediterrani (España); E-mail: eduard.alcaraz@mediterrani.com; https://orcid.org/0000-0003-3895-972X **** Escuela Universitaria Mediterrani (España); E-mail: martasolanoo44@gmail.com; https://orcid.org/0000-0003-1635-472X
} 
aprovechar las preferencias cambiantes de los consumidores (Johns et al., 2017), sino también forjar estrategias eficientes frente a los problemas que derivados de otras cuestiones de tipo tangencial, como las causadas por la turistificación o el turismo de masas (Crespi-Vallbona y Domínguez-Pérez, 2016; García-Henche, 2016).

El objetivo principal de este trabajo es realizar un estudio en profundidad sobre el perfil del consumidor residente local del mercado de La Boquería, el más representativito de la ciudad de Barcelona. Se pretende esclarecer si este emblema ha dejado de ser un comercio de proximidad para convertirse en un atractivo turístico o si sigue ejerciendo la misma función que antaño. La investigación aspira conocer los motivos por los que ha perdido su atractivo y esencia para el público residente local y hasta qué punto el turismo ha podido ser la causa principal. De igual manera, se pretende conocer sus carencias y sus fortalezas, con el fin de aportar soluciones o recomendaciones viables que permitan que La Boquería y mercados similares, tan íntimamente unidos a la cultura mediterránea, puedan hacer frente a los retos venideros.

\section{Marco teórico}

El turismo ha pasado por varias etapas y experimentado numerosos cambios hasta llegar a su concepción contemporánea, cuyo origen se puede establecer en el Gran Tour, una forma de viaje dirigida a jóvenes aristócratas y burgueses que visitaban las ciudades más importantes de Europa cuyo objetivo era ayudar a entender el mundo de forma global a nivel político, social y económico (Molina, 2000; Suárez-Huerta, 2012). En la segunda mitad del siglo XIX emergen los primeros grandes hoteles y se produce el auge de los balnearios (Urkía-Etxabe, 2004; Larrinaga-Rodríguez, 2019; González-Bracco y Pérez-Leloutre, 2020), y las primeras agencias de viajes organizados, que permiten que las clases sociales que están emergiendo en una época postindustrial o de servicios puedan acceder a prácticas turísticas recreativas relacionadas con el paisaje, la cultura, el ocio y las peculiaridades de cada territorio (Cicalase, 2000; Osorio-García, 2010). Estas actividades, en algunos casos, debido a la masificación, han sido causa de procesos de degradación de los recursos naturales y de explotación o malas condiciones laborales de las poblaciones locales que dependen de la actividad (Martín-Hernández, 2009; Haseeb et al., 2018; Balsalobre-Lorente et al., 2020; Lasisi et al., 2020). En las últimas décadas, las mayores transformaciones que han afectado al turismo han emanado de la revolución tecnológica, que ha configurado un nuevo escenario, caracterizado por ofrecer numerosos retos y oportunidades para los destinos turísticos, en el que cada uno de ellos, debido al uso intensivo de información por parte de operadores, intermediarios y público potencial, debe esforzarse por aprovechar sus recursos y potenciarlos (López-Palomeque, 1994; Blanco-Romero y Cànoves-Valiente, 2005; Lee y Wicks, 2010; Calle-Lamelas, 2017; Lee et al., 2018)

En este contexto, la ciudad de Barcelona se ha convertido actualmente en un referente mundial como destino turístico (Montes-Gavilán, 2016; Fernández-Fernández, 2020), situación a la que se ha llegado a pesar de no haber disfrutado de forma directa del Gran Tour como otras ciudades europeas, pero sí de otros movimientos o tendencias de repercusión turística de igual manera importantes como el movimiento romántico, que anhelaba evocar al pasado medieval de la ciudad, el auge de los balnearios y los lugares de ocio termal como promotores del turismo catalán, o la Renaixença, que pretendía redescubrir la identidad catalana y que gracias a una implicación ideológica de la burguesía, junto con su creciente necesidad de ocio, supuso un impulso a los destinos locales (Lavaur, 1987; Boyer, 2002; Tatje-Mir, 2018). Otros factores que también han resultado fundamentales para fomentar el interés de los turistas o para facilitar su llegada a la ciudad han sido la modernización urbanística derivada del Plan Cerdá y del Plan Jaussely y las mejoras de alojamiento, de la red vial y de las estaciones de ferrocarril que supuso la celebración de la Exposición Universal de 1888 (Alcaide-González, 2005; Pallarès-Barberà, 2005; Grandas-Sagarra, 2006; Navas-Ferrer, 2014). Con la apertura de la Transición, tras la dictadura franquista, gracias a eventos como los Juegos Olímpicos de 1992, que sirve para reconstruir la ciudad y mejorar las infraestructuras, y apuestas como la recuperación de la obra de Gaudí y del modernismo en general o la decidida promoción de las instituciones para explotar el potencial turístico de la ciudad, emerge la Barcelona que se ha consolidado desde el final del siglo XX como un destino turístico de masas, llegando a liderar modalidades del tipo todo incluido como la fomentada por el turismo de cruceros (Jiménez y Prats, 2006; Palou-Rubio, 2006; Vidal-Casellas y Crous-Costa, 2013; Garay-Tamajón, 2015).

Así, Barcelona recibe anualmente un número ingente de turistas atraídos por su arquitectura, cultura y gastronomía (Fernández-Fernández, 2020). En concreto, en 2019 el Aeropuerto Josep Tarradellas Barcelona-El Prat registró un movimiento de 52,6 millones de pasajeros, mientras que la ciudad de 
Barcelona recibió la visita de 9.472.562 turistas que realizaron 19.852.416 pernoctaciones (AENA, 2020; Observatori del Turisme a Barcelona, 2020), cifras que ratifican la gran magnitud del fenómeno y que sugieren, en función de su gran evolución al alza de las últimas dos décadas, que esta expansión continuará en el futuro (Duro y Rodríguez, 2015). Debido al incremento de turistas, cuyas actividades durante la estancia afectan a los residentes, produciendo una mercantilización del espacio público que impulsa procesos de gentrificación y provoca especulación inmobiliaria (Abril-Sellarés, Azpelicueta y Sánchez-Fernández, 2015; Zaar y Pontes-da-Fonseca, 2019), en la actualidad, las administraciones públicas sobre las que descansan las competencias en turismo de la ciudad entienden que su futuro ha de pasar por la proyección de planes estratégicos bajo criterios de sostenibilidad, como el Plan Estratégico Metropolitano de Barcelona (PEMB) o el Plan Especial Urbanístico de Alojamiento Turístico (PEUAT), con el fin de poder garantizar que el desarrollo turístico concebido permita fraguar un modelo de ciudad funcional y sostenible, tanto para los ciudadanos locales como para las personas que visitan Barcelona (Crespi-Vallbona y Mascarilla-Miró, 2018; Moreno, Sariego y Ávila, 2018; Fernández-Fernández, 2020).

Los mercados urbanos asentados en un lugar fijo, aunque tienen su origen en la antigüedad, no adquieren su forma contemporánea, tras una intensa renovación, hasta el siglo XIX, al pasar de preocuparse por garantizar las subsistencias básicas a adaptarse a los nuevos hábitos de consumo (García-Domènech, 1985; Lasuén y Baró, 2005; Guardia-Bassols y Oyón-Bañales, 2007; Crespi-Vallbona y Domínguez-Pérez, 2016). En Barcelona, el mercado del Born, hasta entonces al aire libre, desordenado y deficiente, fue el primero que se cubrió, en 1876, para combinar la venta menor y mayor, sirviendo de modelo para la implantación de un nuevo conjunto de mercados locales que siguieron a la anexión de nuevos municipios y el desarrollo del Eixample (Miller, 1993; Cárcamo-Martínez, 2008). Durante el siglo XX, tras la Guerra Civil y la dura época de posguerra, no se construyen nuevos mercados y la falta de mantenimiento hizo desaparecer muchos de ellos, sobre todo tras la apertura progresiva de los supermercados y el concepto self-service, que han provocado la necesidad de plantear y desarrollar estrategias de renovación y transformación de los mercados para adaptarse a los nuevos requerimientos de los clientes (Medina y Álvarez, 2007; Salinas-Arreortua, 2015). En 1991 se crea el Instituto Municipal de Mercados de Barcelona (IMMB) para gestionar la red de mercados a través de diferentes planes estratégicos (actualmente está en vigor el correspondiente al periodo 2015-2025), con el fin de poder hacer frente a las nuevas dinámicas económicas, sociales y tecnológicas (Instituto Municipal de Mercados de Barcelona, 2014).

Los mercados de Barcelona también han sufrido los efectos adversos causados por fenómenos antes referidos como el turismo de masas y la gentrificación, experimentado una transformación urbana de su espacio, en muchas ocasiones bajo estrategias de puesta en valor como recursos turísticos, y la visita continua de viajeros foráneos que, en varios de ellos, paulatinamente han ido desplazando a los vecinos (Hernández-Cordero; 2014; García-Henche, 2016; Hernández-Cordero, 2017). En este sentido, la gradual conversión en atractivos turísticos o la remodelación con este fin de aquellos de especial antigüedad o de los que destacan por su arquitectura, ha venido acompañada de una adaptación a las nuevas prácticas de consumo, como la apuesta por la creación de productos locales gourmet o las nuevas experiencias durante el proceso de compra (Crespi-Vallbona y Domínguez-Pérez, 2016). Entre estos cambios en los hábitos de consumo de alimentos, uno de los más significativos es la no dependencia en la actualidad de la producción local casi en exclusiva como en tiempos pasados, debido a factores como la industrialización, la urbanización, la globalización, la reducción del tamaño de las familias, la incorporación de las mujeres al lugar de trabajo, el aumento de la esperanza de vida tras la jubilación, el incremento del consumo fuera del hogar o la generalización del comercio electrónico (Entrena-Durán, 1997; Laajimi y Albisu-Aguado, 1997; Ponce-Vásquez, 2002; Mili, 2005; Langreo, y Germán, 2018; Ali-Kovero et al., 2020). Esta última variable parece cobrar especial importancia en la comercialización de alimentos de cara al futuro, pues cada agente que opera en este sector deberá adaptarse a las nuevas posibilidades y retos que ofrece este potente y pujante canal para sobrevivir en el mercado (Martínez-Martínez, Fernández-Rodríguez y Saco-Vázquez, 2008; Vallefin, 2018; Alhudaithy, A.I.R. 2019; Puelles et al., 2019; Poelman et al., 2020).

Por su parte, el Mercado de la Boquería es uno de los que mayor expansión y conocimiento popular ha tenido, principalmente a lo largo de todo el siglo XX, disfrutando de sucesivos y ordenados procesos de restauración que conciliaban una progresiva recuperación de la imagen original con su necesaria modernización, concibiendo un espacio donde sus visitantes pudiesen acceder a experiencias de compra claramente diferenciadoras (Medina, 2018; Steegmann, 2018). Todo ello, unido a su privilegiada ubicación dentro de la ciudad le ha convertido en uno de los puntos más emblemáticos de la ciudad de Barcelona, un icono turístico tanto por su valor patrimonial y arquitectónico como inmaterial (Hernández-Cordero 
y Andreeva-Eneva, 2016). Así, la apuesta de las diferentes administraciones por aumentar su atractivo para el consumo turístico ha permitido a los visitantes, gracias a factores como su entorno físico, ubicación y accesibilidad y precio, disfrutar del mercado como si fuesen ciudadanos locales, pero también ha hecho aflorar procesos de gentrificación, turistificación y conflicto urbano en torno al mismo, haciéndolo en cierto modo inaccesible para los propios vecinos del mercado y generando un conflicto social, que, en beneficio del turismo y la economía, ha eludido las posibilidades de prosperidad local (Hernández-Cordero, 2017; Dimitrovski y Crespi-Vallbona, 2018; Cantero-Exojo, 2020).

En este contexto, la pandemia de la COVID-19 ha provocado importantes perjuicios económicos sobre muchos de los mercados locales, sobre todo en aquellos en los que el turismo tenía un peso importante en su facturación, pero también les ha permitido, a pesar de las dificultades, promover los cambios necesarios para que, con las correspondientes medidas efectivas y sostenibles de protección de la salud y de los medios de vida de los comerciantes, se incentivase la compra de productos frescos, de temporada y de proximidad (Carazo-Vargas et al., 2020; Montalvao y Van de Velde, 2020; Pérez-Rodrigo et al., 2020). Desde el Mercado de la Boquería, en concreto, al perder los ingresos provenientes del turismo, desde abril de 2020 se impulsaron acciones para redirigir su producto hacia la población local, potenciando la entrega a domicilio y la venta online, incrementando en gran medida sus ventas (Zerva, 2020).

\section{Metodología}

Con el fin de alcanzar los objetivos pretendidos por la investigación se ha proyectado un estudio de resultados mediante la utilización de métodos mixtos que combinan el análisis cuantitativo y el cualitativo, estimando que sólo con ambas metodologías es posible obtener una visión completa del tema objeto de la investigación (Webb et al. 1966; Denzin, 1978; Bericat, 1998; Forni y De-Grande, 2020). A nivel cuantitativo se ha realizado un estudio de datos procedentes de fuentes primarias a partir de dos encuestas. El análisis de tipo cualitativo practicado en la presente investigación se llevó a cabo a través de siete entrevistas realizadas a personas relacionadas de forma muy estrecha con el mercado de La Boquería.

La primera de las encuestas, con el fin de conocer la percepción de los consumidores locales respecto al turismo y cómo este ha podido influir o no en el mercado de La Boquería, se formalizó sobre una muestra de personas residentes en Cataluña. De la misma manera, se pretendía averiguar cuáles son las tendencias de consumo actuales por parte de los ciudadanos y qué herramientas se podrían utilizar en el ámbito del marketing para proponer posibles mejoras a adoptar con el fin de intentar recuperar la clientela de la ciudad. La muestra de la encuesta llevada a cabo en Cataluña estuvo conformada por 400 individuos de una población aproximada de 6.045.000 habitantes menores de 18 años ${ }^{1}$, por lo que, para un coeficiente de confianza del 95\% y una proporción de la población del 50\%, el error muestral es de $\pm 4,90 \%$. El cuestionario, inspirado en parte por preguntas seleccionadas a partir de un compendio de entrevistas previas realizadas a gestores del Mercado y a diversas personas relacionadas con su actividad por periodistas especializados en economía y empresa de diversos medios de la ciudad de Barcelona, fue construido con criterios académicos, en función de los requerimientos estadísticos y los objetivos del estudio. El formulario de la encuesta se distribuyó de forma telemática a través de aplicación electrónica de creación, edición, envío y procesamiento de encuestas mediante cuentas de correo electrónico y redes sociales, siendo su principal finalidad la interpretación del comportamiento de los encuestados en cuanto a sus hábitos de compra en mercados locales y el conocimiento de su opinión sobre la influencia que el fenómeno turístico y el uso de las redes sociales ejercen sobre su actividad. El plazo para la obtención de 400 respuestas válidas fue de aproximadamente un mes.

El segundo cuestionario se pasó a 123 personas para que, a través de la aplicación UsabilityHub, que permite analizar las páginas web en cuanto a usabilidad y experiencia de usuario, pudiesen llevar a cabo dos pruebas, un first click test, donde los encuestados tenían que seleccionar el punto de la página que más les llamara la atención y argumentar el porqué, y un five second test, en el que, tras visionar una imagen de la home page del mercado de La Boquería durante cinco segundos, se les preguntaba qué apartados del menú recordaban. El tiempo empleado para la realización de esta encuesta fue de dos semanas. Los datos obtenidos en ambas pruebas fueron analizaron de forma estadística, a partir de la generación de tablas dinámicas con el fin de cruzar resultados y extraer conclusiones.

Las entrevistas en profundidad tenían una estructura similar, con el fin de poder comparar la visión de diferentes stakeholders. Se seleccionaron perfiles de diferente tipo que permitieran completar la información obtenida mediante métodos cuantitativos. En concreto, las entrevistas se realizaron a personas que o estaban relacionadas con la gestión del mercado de La Boquería de forma directa o a través de otras instituciones o que trabajaban de forma habitual en el mercado. 


\section{Análisis de resultados}

La encuesta realizada a una muestra de 400 individuos mayores de edad en Cataluña estuvo conformada por un $57,25 \%$ de mujeres y un $42,75 \%$ de hombres. Por grupos de edad, los encuestados entre 18 y 25 años representaron el 8,13\% del total de la muestra, entre 26 y 35 años un 17,82\%, entre 36 y 45 años un 20,48\%, entre 46 y 60 años un $28,32 \%$ y los de más de 60 años un $25,25 \%$. En cuanto al lugar de residencia, el 32\% declaró ser vecino de Barcelona y el 18,75\% del cinturón metropolitano de la ciudad, siendo ambos grupos los que, por proximidad, más probabilidad tienen de ser clientes del mercado de La Boquería. El 49,25\% son del resto de Cataluña, con procedencias muy diversas, representando porcentajes muy pequeños sobre el total de la muestra.

Los resultados obtenidos muestran que sólo un 19\% de los encuestados afirma no haber acudido nunca a comprar a un mercado local. Un $44,75 \%$ han efectuado compras en este tipo de mercados de forma ocasional, un 19\% acuden una o dos veces al mes y un 17,25\% afirman ser clientes regulares que compran semanalmente en estos mercados. Estas cifras confirman que la compra en mercados locales no es la opción más practicada de forma habitual por los encuestados, que probablemente prefieren otras alternativas para adquirir los productos propios de estos establecimientos.

$\mathrm{Al}$ cruzar la frecuencia de compra en mercados locales con el género de los compradores se colige que la compra semanal o mensual es practicada por un $43,81 \%$ de mujeres y un $56,19 \%$ de hombres. Si sólo se consideran los compradores que acuden a comprar de forma mensual, el porcentaje de mujeres (40,74\%) es sustancialmente inferior al de hombres (59,26\%). Sin embargo, esta diferencia se iguala de manera significativa entre aquellos que acuden a los mercados locales semanalmente, con un 49,33\% de mujeres y un 50,67\% de hombres.

Tabla 1: Relación entre la frecuencia de compra en mercados locales y la edad

\begin{tabular}{|l|c|c|c|c|c|}
\hline & $\begin{array}{c}\text { Entre 18 y } \\
\mathbf{2 5} \text { años }\end{array}$ & $\begin{array}{c}\text { Entre 26 y } \\
\mathbf{3 5} \text { años }\end{array}$ & $\begin{array}{c}\text { Entre 36 y } \\
\mathbf{4 5} \text { años }\end{array}$ & $\begin{array}{c}\text { Entre 46 y } \\
\mathbf{6 0} \text { años }\end{array}$ & $\begin{array}{c}\text { Más de 60 } \\
\text { años }\end{array}$ \\
\hline $\begin{array}{l}\text { Clientes habituales } \\
\text { (semanalmente) }\end{array}$ & $8,29 \%$ & $9,52 \%$ & $9,38 \%$ & $27,16 \%$ & $52,94 \%$ \\
\hline $\begin{array}{l}\text { Compra una o dos } \\
\text { veces al mes }\end{array}$ & $16,56 \%$ & $18,10 \%$ & $21,88 \%$ & $19,75 \%$ & $29,41 \%$ \\
\hline $\begin{array}{l}\text { Cliente ocasional, no } \\
\text { habitual }\end{array}$ & $49,68 \%$ & $52,38 \%$ & $46,88 \%$ & $45,68 \%$ & $5,88 \%$ \\
\hline $\begin{array}{l}\text { No compra nunca en } \\
\text { los mercados locales }\end{array}$ & $25,48 \%$ & $20,00 \%$ & $21,88 \%$ & $7,41 \%$ & $11,76 \%$ \\
\hline
\end{tabular}

Fuente: Elaboración propia a través de los datos de la encuesta

Si se cruza la frecuencia de compra en mercados locales con la edad, se puede inferir que en la actualidad existe una propensión hacía la reducción de la frecuencia de compra en los mercados locales, puesto que es predominante la figura de cliente ocasional en todos los grupos de edad excepto en las personas de más de 60 años, que parecen mostrar cierta rutina de compra en estos establecimientos (tabla 1). Los datos de este grupo corroboran que estas personas ejercen una relación con los mercados locales muy diferente a la del resto de grupos, sobre todo con los más jóvenes (Fig. 1). En concreto, tan sólo un 17,65\% de los mayores de 60 años admite no comprar nunca en estos mercados o hacerlo de forma ocasional, un $29,41 \%$ lo hace una o dos veces al mes y el 52,94\% acude regularmente cada semana. Por otra parte, muchos de estos encuestados manifiestan acudir todavía a los mercados locales para encontrar productos frescos o de buena calidad, así como para apoyar el comercio local y de proximidad. Por el contrario, quienes no suelen comprar en ellos es porque, no dan excesivo valor a la venta personalizada y prefieren otros tipos de tiendas con horarios más amplios, como supermercados e hipermercados. 
Figura 1: Frecuencia de compra en mercados locales según edad

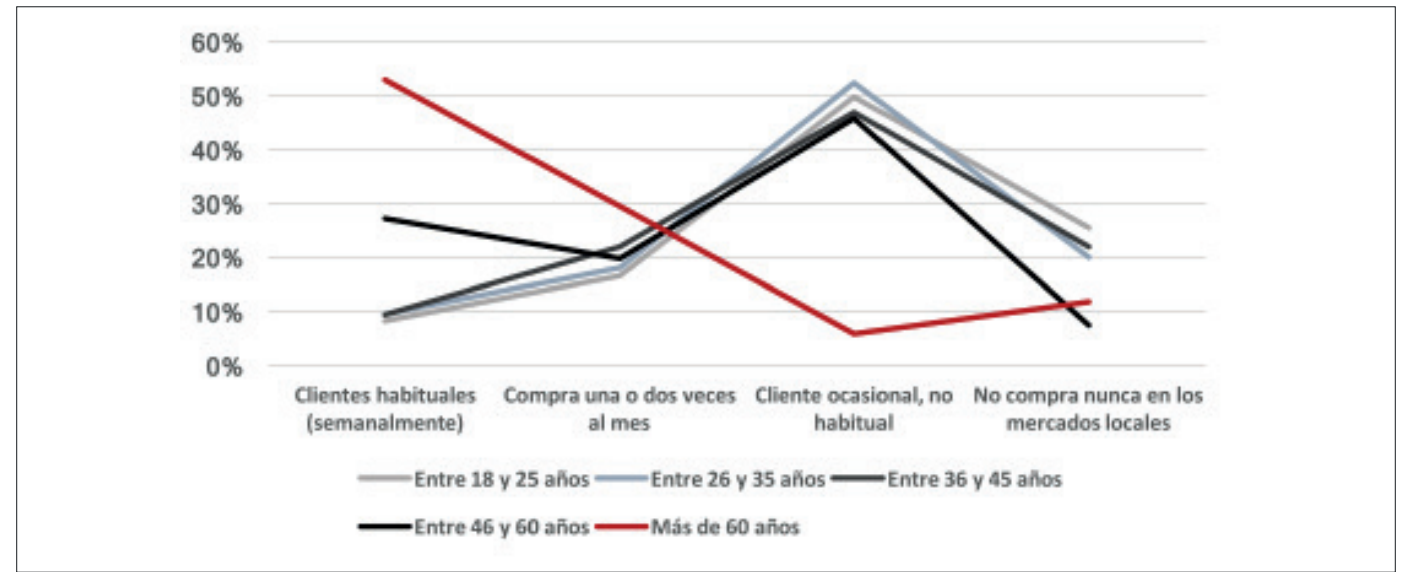

Fuente: Elaboración propia a través de los datos de la encuesta

Por otro lado, si se cruzan los datos de quienes compran en los mercados locales semanal o mensualmente (el 36,25\% del total de la muestra) con su situación laboral, los datos revelan que el 48,97\% son asalariados, el $18,62 \%$ son estudiantes y asalariados a un mismo tiempo, el 15,17\% son autónomos, el 13,79\% estudiantes y el 3,45\% manifestaron encontrarse desempleados. De estas cifras se puede deducir una mayor predisposición a la compra en mercados locales en individuos con mayor poder adquisitivo o disfrutando de un salario fijo.

Interpelados los encuestados sobre las razones que les impulsan a comprar en estos mercados, las respuestas más frecuentes hacían referencia a variables como la costumbre, proximidad, calidad de los productos, carácter de comercio local y posibilidad de comprar productos frescos, tradicionales y únicos. Quienes no suelen acudir a los mercados lo fundamentan en los precios elevados, la menor accesibilidad con respecto a otro tipo de establecimientos, la incompatibilidad horaria, la lentitud de la venta personalizada y la preferencia por comercios como los supermercados o hipermercados.

Puesto que para la muestra en su conjunto el nivel de conocimiento del mercado de La Boquería fue bastante alto (97\% aproximadamente), una cuestión relevante fue conocer la percepción de la calidad de los productos vendidos (Fig. 2), resultando que para la mayor parte de los encuestados esta era buena (52,94\%) o muy buena (25\%), siendo muy pocos quienes optaron por valorarla de forma negativa $(2,95 \%)$. Así, la valoración media ponderada de la calidad de los productos fue de 3,99 puntos sobre 5, cifra que revela la buena reputación del mercado y de la calidad de sus productos.

Figura 2: Percepción de la calidad del producto vendido en el mercado

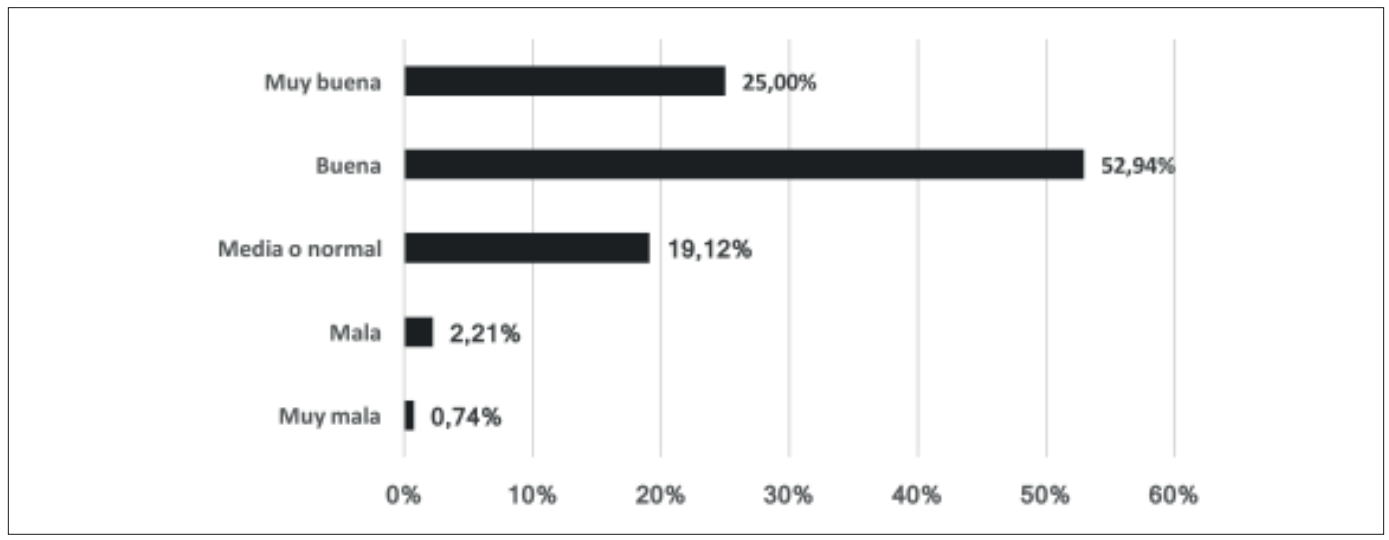

Fuente: Elaboración propia a través de los datos de la encuesta 
En cuanto al efecto que la alta afluencia de turistas al mercado de La Boquería pudiera tener sobre la captación de clientes locales, un $73,25 \%$ opinó que era negativa, mientras que un 12,50\% pensaba que tenía una influencia positiva y un $14,25 \%$ consideraba que no afectaba de ningún modo. Al realizar este análisis sólo con residentes en Barcelona, los resultados obtenidos son prácticamente similares. Un dato bastante revelador es que entre los encuestados que estimaban que el turismo tiene una influencia negativa, el 93,33\%, nunca van a comprar a La Boquería o sólo lo hacen de forma esporádica.

Otra de las cuestiones sobre las que se interpeló a los encuestados fue sobre cómo estimaban que afectaba la masificación turística de La Boquería a su reputación (tabla 2). Al contrario que en la cuestión anterior, los encuestados sí mostraron una valoración más positiva sobre la influencia del turismo en este sentido, ya que un $55 \%$ así lo estimaba, mientras que un $28,50 \%$ opinaba que influía negativamente. Al cruzar las respuestas a esta cuestión con el lugar de residencia, el porcentaje de vecinos de Barcelona que creían en una influencia positiva del turismo sobre la reputación del mercado decrecía en un 4,62\% con respecto al total de la muestra, a la par que se incrementaba notablemente, un $26,55 \%$, el porcentaje de quienes estimaban una influencia negativa. Esta circunstancia sugiere que fenómenos como la turismofobia tienden a arraigar de manera más persistente en comunidades que soportan más directamente los efectos más negativos del turismo. En este contexto, resulta significativo que el $62,25 \%$ de los participantes en el estudio consideraban que el mercado ha perdido su esencia original, por sólo un $34,75 \%$ que entendían que, a pesar de los efectos del turismo, esta se ha mantenido intacta. Sobre este particular, la aplicación de restricciones de acceso al mercado a grupos con guía de más de 15 turistas fue acogida de forma muy positiva, ya que el 58,50\% opinaba que era una buena o muy buena medida. La media ponderada obtenida sobre esta cuestión fue de 3,70 puntos sobre 5 .

\section{Tabla 2: Influencia de la alta afluencia de turistas sobre la reputación del mercado de La Boquería. Total muestra versus residentes en Barcelona}

\begin{tabular}{|l|c|c|c|}
\hline & Total muestra & $\begin{array}{c}\text { Residentes } \\
\text { Barcelona }\end{array}$ & Diferencia \\
\hline $\begin{array}{l}\text { Proporciona una buena } \\
\text { reputación al mercado }\end{array}$ & $55,00 \%$ & $52,46 \%$ & $-4,62 \%$ \\
\hline $\begin{array}{l}\text { Proporciona una mala } \\
\text { reputación al mercado }\end{array}$ & $28,50 \%$ & $36,07 \%$ & $26,55 \%$ \\
\hline $\begin{array}{l}\text { No proporciona ni buena ni } \\
\text { mala reputación }\end{array}$ & $16,50 \%$ & $11,48 \%$ & $-30,45 \%$ \\
\hline
\end{tabular}

Fuente: Elaboración propia a través de los datos de la encuesta

En cuanto al conocimiento y uso de la página web y las redes sociales de La Boquería, el estudio determinó que el $87,50 \%$ de los encuestados nunca había visitado la página web oficial del mercado y que el pequeño porcentaje que sí lo había hecho lo hizo para conocer los horarios o buscar el emplazamiento de puestos de venta o productos específicos. Con respecto a las redes sociales, el mercado cuenta con perfil oficial en Instagram, Facebook y Twitter. El 97\% de los participantes en el estudio declaró no seguir ninguna de estas cuentas y sólo un 2,50\% era seguidor de la de Facebook, un 1,25\% de la de Instagram y un $0,25 \%$ de la de Twitter, cifras muy bajas, sobre todo considerando que la mayor parte de las acciones en redes se dirigen al público local y no al turismo extranjero. Al interpelar a los encuestados sobre una posible falta de presencia efectiva en redes del mercado, solamente un 10,45\% apreció el actual escenario como suficiente, apostando la mayoría por potenciarlas. La opción preferida en este sentido, en una consulta de respuesta múltiple, fue Instagram (79,75\%), seguida de Facebook (25,50\%), Twitter (20\%) y YouTube (14,75\%). Así mismo, con posibilidad de respuesta múltiple, entre las diversas opciones posibles para incrementar la presencia online del mercado, el 81,50\% se decantó por realizar descuentos y promociones, el $41,50 \%$ por sorteos y concursos, el 19,25\% por el envío de boletines (newsletters) y el 9,75\% por utilizar landing page específicas. 


\section{Figura 3: Test First Click de la ficha de una parada en la página web del mercado de La Boquería}

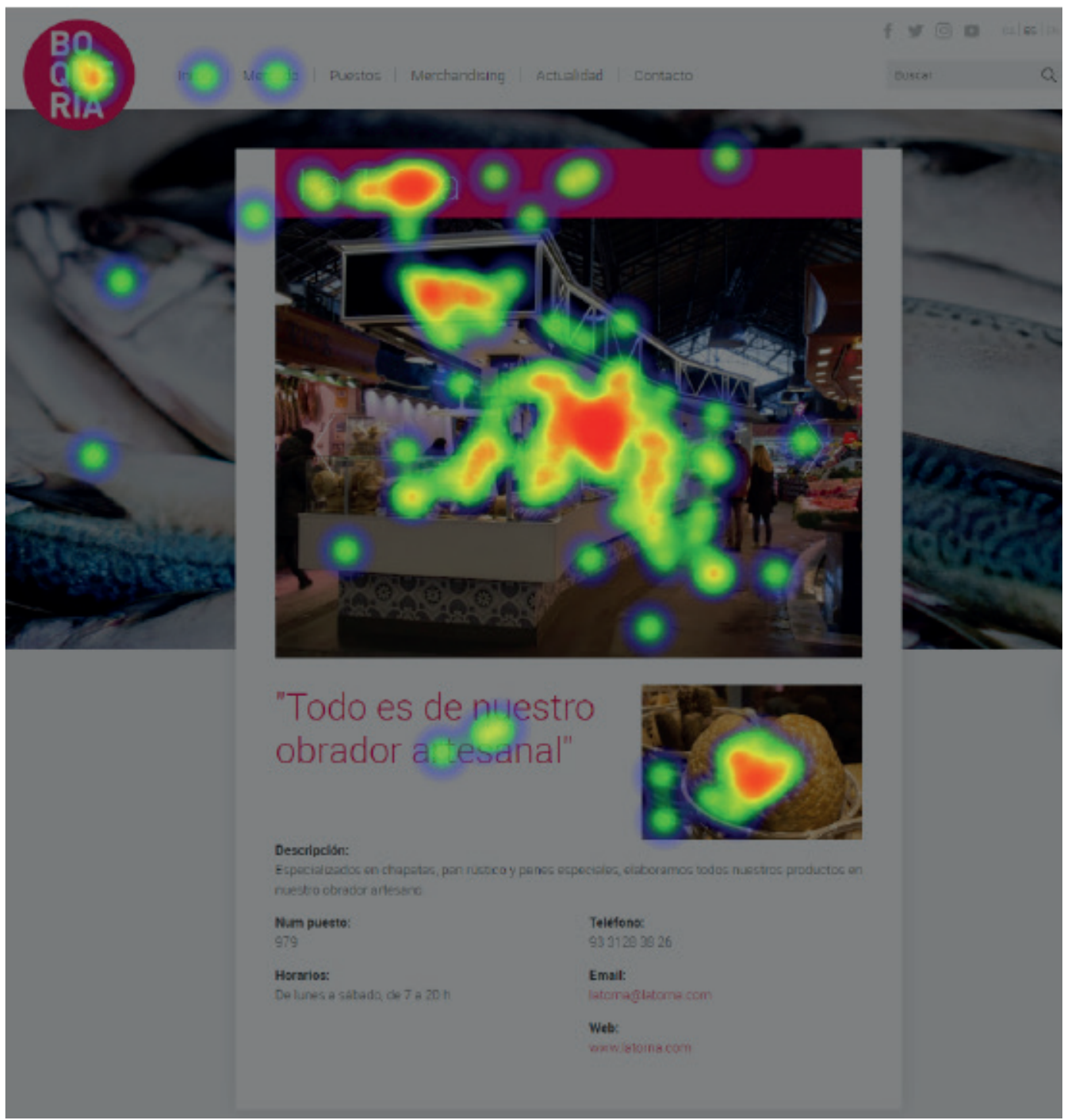

Fuente: Elaboración propia a partir de página web del mercado de La Boquería

Por otro lado, con el fin de determinar los aspectos a mejorar en el diseño de la página web de La Boquería se realizó una segunda encuesta a 123 individuos para que llevar a cabo, mediante la aplicación UsabilityHub, un first click test y un five second test. La primera prueba se efectuó sobre la ficha de producto de un puesto (parada) del mercado. Los participantes debían pulsar sobre aquello que más les atrajera de la página presentada, interrogándoles después sobre los motivos por los que pulsaron en ese punto concreto. Tal y como se puede observar en el mapa de calor obtenido (Fig. 3), la mayor parte de los participantes optó por pulsar sobre la imagen del puesto, la del producto, el nombre del puesto o el logotipo de la web.

Como las preguntas efectuadas con relación al test eran de respuesta abierta, se tuvo que realizar una comparativa sistemática, agrupándolas por categorías, para poder hacer un análisis eficiente y 
extraer propuestas de mejora útiles. Así, fue posible inferir que quienes pulsaron sobre la imagen de la parada lo hicieron porque es lo que más llama la atención, prevaleciendo las fotografías sobre el texto. Quienes pulsaron sobre el logotipo de La Boquería o el nombre o el eslogan del puesto afirman haberlo hecho debido al color llamativo (donde primero se va la vista), o por proximidad a las referencias al producto ofrecido. Los que optaron por seleccionar alguna categoría del menú lo hicieron porque es lo que hacen habitualmente cuando navegan o porque preferían visitar otra sección. De forma general, se puede afirmar que las imágenes prevalecen por encima del texto, cuando lo que debería resaltar es la ficha de la parada y la información proporcionada y no su fotografía, ya que aparte de mostrar su disposición no aporta ninguna información relevante. En cualquier caso, la utilización de colores vivos o formas como el logotipo redondo, que rompen con la estética clásica de las páginas web captando la atención de los usuarios, siempre es recomendable.

Figura 4. Home page del Mercado de La Boquería

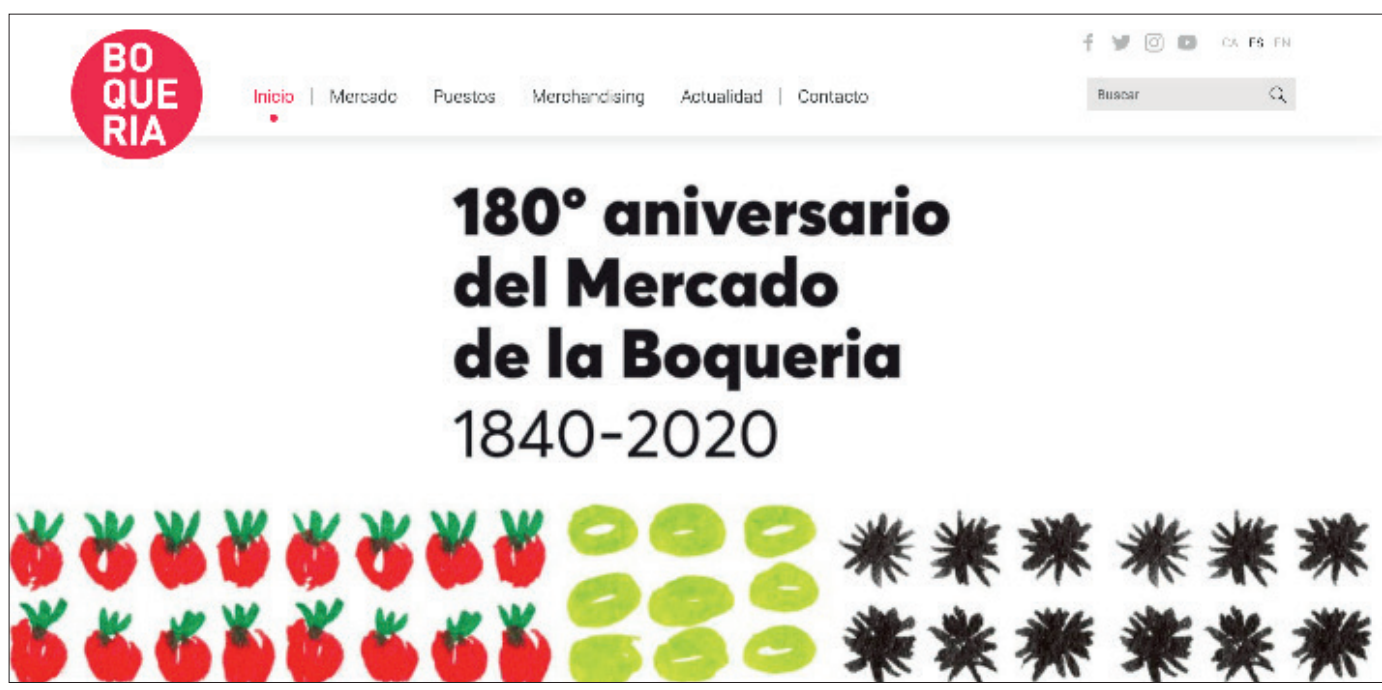

Fuente: Home Page del mercado de La Boquería ${ }^{2}$

La segunda de las pruebas consistió en un five second test, donde a los participantes, tras visionar durante cinco segundos la imagen de la Home Page del mercado (Fig. 4), se les preguntó sobre las secciones del menú que recordaban. De forma similar a la anterior prueba, las preguntas eran de respuesta abierta, por lo que hubo que categorizarlas. Sólo el 4,88\% de los individuos fue capaz de recordar algunos de los apartados del menú, ya que la imagen que aparecía como promocionando el $180^{\circ}$ aniversario de La Boquería captaba mucho más la atención. De hecho, el 74,80\% de los encuestados recordaban el mensaje y los iconos de los alimentos que aparecen en la imagen. Este test reproducía, pues, los resultados obtenidos en la prueba precedente, ya que la atención de los usuarios se fijaba en las imágenes por encima del texto. Esta circunstancia es relevante ya que, cuando desde La Boquería se desee comunicar una información o realizar promociones, debe considerarse que esta ubicación tiene un impacto muy alto, alcanzando a la mayoría de quienes navegan por la página.

Por último, se llevó a cabo un análisis de tipo cualitativo a partir de siete entrevistas a personas relacionadas de alguna manera con la gestión de La Boquería: el gerente del mercado, una guía turística, la responsable de marketing, el director de planificación estratégica de mercados del IMMB, el responsable de dinamización estratégica de la Fundación Barcelona Comercio (FBC) y dos paradistas del mercado (tabla 3). Todos ellos participan en las labores de promoción del mercado, ya sea a nivel institucional o a través de sus propios perfiles en redes sociales (como los dos comerciantes o la guía). Algunos de los entrevistados tienen relación profesional y responsabilidades sobre otros mercados locales. Los tres perfiles que admiten sufrir las consecuencias negativas de turismo masificado son la guía y los dos propietarios de los puestos. 


\section{Tabla 3. Comparación de perfiles de encuestados}

\begin{tabular}{|l|c|c|c|}
\hline Cargo & $\begin{array}{c}\text { Relación con } \\
\text { otros mercados } \\
\text { locales }\end{array}$ & $\begin{array}{c}\text { Relación con } \\
\text { acciones de } \\
\text { promoción de La } \\
\text { Boquería }\end{array}$ & $\begin{array}{c}\text { Soporta } \\
\text { consecuencias } \\
\text { masificación } \\
\text { turística }\end{array}$ \\
\hline Gerente General de La Boquería & No & Sí & No \\
\hline Guía & No & Sí & Sí \\
\hline $\begin{array}{l}\text { Responsable de Marketing de La } \\
\text { Boquería }\end{array}$ & No & Sí & No \\
\hline $\begin{array}{l}\text { Director de Planificación } \\
\text { Estratégica de Mercados (IMMB) }\end{array}$ & Sí & Sí & No \\
\hline $\begin{array}{l}\text { Responsable de la dinamización } \\
\text { estratégica de la Fundació } \\
\text { Barcelona Comerç (FBC) }\end{array}$ & Sí & Sí & Sí \\
\hline Paradista Faláfel Vegano & No & Sí & Sí \\
\hline Paradista El Racó de La Paqui & No & \multicolumn{2}{|c|}{ Pán } \\
\hline
\end{tabular}

Fuente: Elaboración propia a partir de las entrevistas realizadas

El análisis conjunto de las entrevistas realizadas arroja una primera cuestión en la que todos los encuestados están de acuerdo, que son los muchos y sucesivos cambios que el mercado ha soportado en las últimas décadas, muchos determinados por la apertura al exterior de Barcelona, producida principalmente desde los Juegos Olímpicos de 1992. Evidentemente, a pesar de que se ha hecho necesario gestionar muchas más visitas, sobre todo de turistas, el espacio físico donde se ubica el mercado sigue siendo muy pequeño. Aun así, el director de planificación estratégica de mercados del IMMB advierte que La Boquería no debería concebirse como un pilar turístico, sino que, gracias a su ubicación en La Rambla y a su relación intrínseca con la gastronomía mediterránea, debería ser un icono, no tanto del turismo, sino de la historia de la ciudad.

Para poder gestionar la masificación turística y preservar la calidad del mercado se aprobó en 2017 un plan de actuación específico que ha permitido mejorar en temas relacionados con la limpieza, iluminación, salidas de humo, vigilancia y gestión de la afluencia de turistas. Evidentemente, como señala el gerente del mercado, La Boquería evoluciona a la par que lo hace Barcelona. En este sentido, los dos comerciantes entrevistados señalan que han tenido que saber adaptarse a los nuevos requerimientos de la clientela, cambiando productos que antes se vendían muy bien para el público local y que no son demandados por los visitantes actuales. Por su parte, el responsable de la dinamización estratégica de la FBC apunta que para que La Boquería no quedara desbordada por el turismo y se pudiera favorecer las visitas del público local, se ha incluido al mercado dentro del eje comercial del Raval. El objetivo es preservar un modelo de barrio y ciudad equilibrada y viva, manteniendo su esencia a través del comercio de proximidad, los servicios y la restauración. Puesto que la gentrificación amenaza la propia esencia de la ciudad, se trata de defender un mix comercial equilibrado, apostando por descentralizar el turismo y repartir sus costes y beneficios entre los diferentes distritos. Desde la gerencia de La Boquería se advierte que uno de los mayores problemas a los que se enfrenta actualmente el mercado es la apuesta que la reglamentación municipal hace en favor del producto fresco, obligando a los comerciantes a ofertarlo en gran cantidad, quedando, en muchas ocasiones, sin vender, provocándoles grandes pérdidas. Una solución podría ser fomentar la degustación de productos, tipo take away, disfrutando de la experiencia de una manera digna o de calidad y combinándolo con una oferta de producto fresco.

La promoción digital de La Boquería se lleva a cabo por el propio mercado, el IMMB y la FBC. La Boquería utiliza su página web, Instagram, Facebook y Twitter y se orienta casi en exclusiva al público local, utilizando técnicas de inbound marketing, procurando exponer sus valores de manera no intrusiva. El IMMB efectúa acciones de difusión y promoción, dirigidas principalmente a residentes de Barcelona. La FBC prioriza su función de lobby del comercio de proximidad y de análisis de tendencias y prospectiva de retos futuros. Los dos comerciantes entrevistados están presentes en Instagram con cuentas no muy activas en las que no se realiza ningún tipo de sorteos, concurso o promoción.

En general, el total de los entrevistados manifiesta tener un cierto grado de preocupación por el fenómeno turístico, ya que, aunque, como advierten los dos paradistas, el $80 \%$ de la venta actual se 
dirige al turismo, su explotación en exceso es perjudicial y convierte al mercado en una especie de parque temático, provocando que demasiados puestos oferten productos similares dirigidos principalmente al turismo, incrementando la competencia entre ellos. A ello hay que unir fenómenos de incivismo y violencia, que han afectado negativamente a la identidad del mercado. Los cambios de tendencia del consumo de las últimas décadas han provocado además que más que competir con el modelo de los supermercados, haya que convivir con él, ya que la red de este tipo de establecimientos es amplísima y se sitúan para la mayor parte del público mucho más cerca de sus domicilios que los mercados locales. La diversificación de la oferta y el fomento de la venta online podrían ser una oportunidad en este sentido, más aún tras la crisis de la COVID-19. Con relación a la restricción de la entrada de grupos de más de 15 turistas con guía en determinadas franjas horarias prácticamente todos están de acuerdo en que se trata de una medida positiva, que beneficia sobre todo a la circulación por los puestos del interior, aunque estiman que esta normativa no es muy efectiva, ya que muchos grupos se separan antes de acceder al mercado.

\section{Conclusiones}

El objetivo principal de esta investigación era analizar el perfil del consumidor residente local en el mercado de La Boquería, tratando de conocer el grado de influencia que la masificación del turismo en Barcelona y la conversión en atracción turística del mercado han tenido como determinantes del alejamiento del público local. Además, se pretendía indagar en las razones por las que se ha perdido esa clientela, explorando las posibles mejoras a adoptar con el fin de intentar recuperarla. Los resultados obtenidos a partir de las encuestas y las entrevistas practicadas en el curso de la investigación determinan que las razones de la pérdida del público local de los mercados en general y de La Boquería en particular son diversas, como la aparición de nuevos tipos de establecimientos comerciales y los cambios en el consumo, así como una tendencia descendente generalizada a comprar (quizás con la única excepción de los clientes de mayor edad) en todos los mercados locales, que han tenido que adaptarse y reinventarse según las nuevas necesidades de los clientes y la evolución de la ciudad. En este sentido, resulta especialmente relevante el testimonio de los comerciantes de La Boquería apuntando a la incidencia del incivismo y la violencia en el barrio como causa de la pérdida de su identidad y de que los vecinos no acudan al mercado.

Existen divergencias notables entre las opiniones de los encuestados con respecto a la bondad del turismo, ya que es una opinión bastante extendida que el auge turístico impide, por un lado, la captación de clientes locales, pero, al mismo tiempo, proporciona una buena reputación tanto al mercado como a la ciudad. Lo que resulta evidente es que, debido a ello, los mercados locales han tenido que llevar a cabo numerosos cambios para adaptarse y poder sobrevivir, concibiéndose como espacios donde los visitantes no sólo acuden a comprar, sino también a disfrutar de experiencias. El perfil clásico de consumidor que los fines de semana accedía a comprar a los mercados está en declive y acabará desapareciendo para dejar paso a las nuevas generaciones que presentan otras necesidades. Por este motivo, muchos mercados han introducido la degustación de productos o incluso la apertura de restaurantes para abastecer este nuevo tipo de demanda.

En este contexto de constante renovación, La Boquería ha conservado la percepción de calidad de su producto, como pone de manifiesto la valoración de 3,99 sobre 5 que la encuesta arroja para este indicador, reafirmando la reputación del mercado. A pesar de este dato positivo, el 62,25\% de los encuestados estiman que el mercado, debido a los factores señalados, ha perdido su esencia en gran parte, ocasionando una pérdida de la clientela local en favor del turismo. De hecho, incluso los propios comerciantes del mercado llegan a tener la impresión de que se ha convertido en un parque temático. En cualquier caso, la mayoría de entrevistados piensan que La Boquería debe seguir evolucionando y que, aunque la venta online seguirá ganando presencia, no ha de ser el único aspecto a fijarse para garantizar la supervivencia de estos establecimientos. En este sentido, resulta fundamental el desarrollo de procesos de planificación estratégica, no sólo desde el mismo mercado, sino también a través de instituciones como el IMMB, el Ayuntamiento de Barcelona o la FBC.

Es posible que las instituciones rectoras del mercado de La Boquería y los propios comerciantes debieran adquirir una mayor conciencia sobre la importancia que en la actualidad tienen las redes sociales en las estrategias comerciales. En general, los vendedores apenas promocionan sus comercios ni llevan a cabo ninguna clase de acción de marketing, perdiendo la oportunidad de dirigirse a un target mucho más joven, que, en definitiva, no dejan de ser sus potenciales futuros clientes. Se debería potenciar la utilización de cada red en función del público objetivo, ya sea Instagram en el caso de los millennials, o Facebook y Twitter, para públicos de mayor edad. De hecho, los encuestados señalan que, si la política de comunicación de las redes sociales del mercado se afrontara de diferente manera, muchos de ellos 
se harían seguidores. Sería un error que, en este ámbito, por seguir anclados exclusivamente en un tipo de comunicación muy tradicional, se pierda la oportunidad de enseñar a las nuevas generaciones la importancia del comercio de proximidad y de la gastronomía y cultura mediterránea.

Otro aspecto que La Boquería debería considerar es la renovación de su página web. Los resultados obtenidos de la herramienta UsabilityHub aconsejan la modificación del diseño de las fichas de los puestos. Sería conveniente una estructura que proporcione un valor añadido a la página web, con respecto a nivel de experiencia de usuario y de navegación, mediante la utilización de colores vistosos en los apartados del menú y en la ficha de cada puesto, con unas descripciones detalladas que contengan imágenes de los productos ofertados. Sería interesante también adaptar la navegabilidad de la página $w e b$ a personas con discapacidades, en la línea de otros mercados nacionales e internacionales.

El turismo, casi con toda probabilidad, seguirá siendo un factor determinante para marcar el rumbo que seguirá La Boquería. En la línea de conciliar aspectos aparentemente divergentes, como la recuperación de la imagen tradicional con la necesidad de modernizarse o la conversión en un icono turístico con el deseo de recuperar el público local, se debe poner en valor su privilegiada ubicación dentro de la ciudad, tanto en beneficio del turismo como en la consecución de prosperidad local. Para ello, se debe apostar por la recuperación de gran parte de la esencia tradicional, realzando el comercio de proximidad, a la vez que se trabaja por continuar adaptándose a las necesidades de los clientes, locales y foráneos, y a los nuevos retos que sin duda deparará el futuro. En este sentido, la pérdida de la facturación derivada de la caída del turismo en la ciudad de Barcelona como consecuencia de la pandemia de la COVID-19 ha puesto de manifiesto la oportunidad de, por un lado, revisar los patrones de uso y consumo para replantear el uso del espacio y, por otro, de recuperar parte del público local que había abandonado La Boquería mediante el impulso de acciones para redirigir su producto hacia este tipo de población, como el fomento de la entrega a domicilio y la venta online.

La elaboración de la presente investigación se encontró como principal limitación la coincidencia en su fase de trabajo de campo con el periodo de confinamiento poblacional de la primavera de 2020 , lo cual imposibilitó la realización de visitas y entrevistas presenciales ya agendadas, impidiendo el contacto con algunos comerciantes reacios al uso de medios digitales o las videollamadas, cuya opinión hubiese sido de interés. Este trabajo ha pretendido contribuir a despejar muchas de las incógnitas que planteaba el estudio, abriendo también, de forma simultánea, nuevos interrogantes que conducen a futuras líneas de investigación. Entre estas, dada la situación socioeconómica generada por la pandemia de COVID-19 en el momento de elaboración del artículo, resulta de especial interés para los investigadores el análisis en profundidad de la comparativa del funcionamiento operacional de La Boquería antes y después de la pandemia, así como el de los avances realizados a partir de la misma en cuanto a la digitalización del propio mercado.

\section{Bibliografía}

Abril-Sellarés, M., Azpelicueta, M.C. y Sánchez-Fernández, M.D. 2015. “Turismo sostenible: lugareños frente a turistas. El caso de la ciudad de Barcelona”. Holos, 3: 331-337.

AENA 2020. El Aeropuerto Josep Tarradellas Barcelona-El Prat registra 52,6 millones de pasajeros en 2019. Aeropuertos Españoles y Navegación Aérea, Nota de Prensa. https://bit.ly/2XaBTTR (Consultado el 30/07/2020).

Alhudaithy, A.I.R. 2019. "The impact of supermarkets' mobile application on Saudi customer's behavior during the buying decision process". Expert Journal of Marketing, 7(1): 77-91.

Ali-Kovero, K., Pietiläinen, O., Mauramo, E., Jäppinen, S., Rahkonen, O., Lallukka, T. y Kanerva, N. 2020. "Changes in fruit, vegetable and fish consumption after statutory retirement: a prospective cohort study". British Journal of Nutrition, 123(12): 1390-1395.

Alcaide-González, R. 2005. "El Ferrocarril como elemento estructurador de la morfologia urbana: el caso de Barcelona 1948-1900”. Scripta Nova. Revista Electrónica de Geografía y Ciencias Sociales, IX, 194(65).

Balsalobre-Lorente, D., Driha, O.M., Shahbaz, M. y Sinha, A. 2020. "The effects of tourism and globalization over environmental degradation in developed countries". Environmental Science and Pollution Research, 27(7): 7130-7144.

Bericat, E. 1998. La integración de los métodos cuantitativo y cualitativo en la investigación social: Significado y medida. Barcelona: Ariel.

Blanco-Romero, A. y Cànoves-Valiente, G. 2005. "Las tecnologías de la información y la comunicación en el desarrollo del turismo rural". Documents d'Anàlisi Geogràfica, 46: 105-117.

Boyer, M. 2002. "El turismo en Europa, de la edad moderna al siglo XX". Historia Contemporánea, 25: 13-31. 
Calle-Lamelas, J.V. 2017. "Revolución Big Data en el turismo: análisis de las nuevas fuentes de datos para la creación de conocimiento en los Destinos Patrimonio de la Humanidad de España”. International Journal of Information Systems and Tourism (IJIST), 2(2): 23-39.

Cantero-Exojo, M. 2020. "Semiotic landscapes and discourses of protest in Barcelona: Tourism Kills". Moderna Språk, 114 (Special Issue): 145-175.

Carazo-Vargas, E., Muñoz-Calvo, F., Gatica-López, G. y García-Fonseca, T. 2020. "Seguridad y soberanía alimentaria frente al COVID-19". Revista Rupturas, 10: 45-50.

Cárcamo-Martínez, J. 2008. "Nueva vida para los mercados de hierro en la Península Ibérica". En M.Á. Álvarez-Areces (coord.). Del hierro al acero: forjando la historia del patrimonio industrial metalúrgico (pp. 129-137). Gijón: Centro de Iniciativas Culturales y Sociales, CICEES.

Cicalase, G.G. 2000. "Los cambios de sentido en los espacios sociales del turismo a partir de la globalización”. FACES, Revista de la Facultad de Ciencias Económicas y Sociales, 6(8): 79-106.

Coronas, J. 2019. "Envíos más rápidos, más ecológicos y a cualquier lugar". Emprendedores, 260: 87-93.

Crespi-Vallbona, M. y Domínguez-Pérez, M. 2016. "Los mercados de abastos y las ciudades turísticas". PASOS: Revista de Turismo y Patrimonio Cultural, 14(2): 401-416.

Crespi-Vallbona, M. y Mascarilla-Miró, Ó. 2018. "La transformación y gentrificación turística del espacio urbano. El caso de la Barceloneta (Barcelona)”. EURE, Revista Latinoamericana de Estudios Urbano Regionales, 44(133): 51-70.

Denzin, N. 1978. The Research Act. Nueva York: McGraw Hill.

Dimitrovski, D. y Crespi Vallbona, M. 2018. "Urban food markets in the context of a tourist attraction. La Boquería market in Barcelona, Spain”. Tourism Geographies, 20(3): 397-417.

Diputació de Barcelona 1986. Pla Especial de l'Equipament Comercial Alimentari a la Ciutat de Barcelona. Bolletí Oficial de la Província, nº 130, 9-15.

Duro, J. y Rodríguez, D. 2015. "Barcelona como municipio turístico: algunos datos evolutivos y elementos de futuro". Documents d'Anàlisi Geogràfica, 61(3): 507-538.

Entrena-Durán, F. 1997. "Cambios en las pautas de consumo alimentario en España”. Papers: Revista de Sociología, 51, 201-214.

Espinosa-Seguí, A. 2009. El comercio como herramienta estructuradora del territorio. El caso de las ciudades alicantinas. Universidad de Alicante, Tesis Doctoral.

Fernández-Fernández, J. 2020. "El turismo sostenible en España: análisis de los planes estratégicos de sostenibilidad de Zaragoza y Barcelona”. ROTUR, Revista de Ocio y Turismo, 14(1): 94-106.

Forni, P. y De-Grande, P. 2020. "Triangulación y métodos mixtos en las ciencias sociales contemporáneas". Revista Mexicana de Sociología, 82(1), 159-189.

Garay-Tamajón, L.A. 2015. "Luces y sombras del turismo de cruceros: el caso de Barcelona". Documents d’Anàlisi Geogràfica, 61(3): 563-580.

García-Domènech, R. M. 1985. "Mercats de Barcelona a la primera meitat del segle XIX". En Història urbana del Pla de Barcelona: Actes del II Congrés d'Història del Pla de Barcelona celebrat a l'Institut Municipal d'Història, 2 (pp. 191-207). Barcelona: Institut Municipal d'Història.

García-Henche, B. 2016. "Los mercados de abastos como espacios de turismo experiencial: el caso de la ciudad de Madrid". Revista Turismo y Desenvolvimento, 25: 89-101.

Gracia, M.C. y Huertas-García, R. 2016. "Decision making and erotic stimuli: An evolutionary perspective". Spanish Journal of Marketing-ESIC, 20(1): 30-40.

Grandas-Sagarra, C. 2006. "Arquitectura para una exposición: Barcelona 1929”. Artigrama, 21, 105-123.

González-Bracco, M. y Pérez-Leloutre, S. 2020. "Distinción, descanso y confort: los grandes hoteles como avanzada de la Argentina turística (1886-1914)". Claves, Revista De Historia, 6(10): 7-35.

Guardia-Bassols, M. y Oyón-Bañales, J. L. 2007. "Los mercados públicos en la Ciudad contemporánea. El caso de Barcelona". Biblio 3W: Revista Bibliográfica de Geografía y Ciencias Sociales, 12(744): 1-11.

Haseeb, M., Hassan, S., Azam, M. y Suryanto, T. 2018. "The dynamics of governance, tourism and environmental degradation: the world evidence". International Journal of Global Environmental Issues, 17(4): 340-363.

Hernández-Cordero, A. 2014. "Gentrificación comercial y mercados públicos: El Mercado de Santa Caterina, Barcelona”. Working Paper Series Contested Cities, 14017: 1-17.

Hernández-Cordero, A. y Andreeva-Eneva, S. 2016. “¿Mercados, museos o malls? La gentrificación de los mercados municipales en Barcelona y Madrid”. EntreDiversidades: Revista de Ciencias Sociales y Humanidades, 6: 143-173.

Hernández-Cordero, A. 2017. "Los mercados públicos. Espacios urbanos en disputa”. Iztapalapa: Revista de Ciencias Sociales y Humanidades, 38(83): 165-186. 
Huitink, M., Poelman, M.P., Van den Eynde, E., Seidell, J.C. y Dijkstra, S.C. 2020. "Social norm nudges in shopping trolleys to promote vegetable purchases: A quasi-experimental study in a supermarket in a deprived urban area in the Netherlands". Appetite, 151: 1-7.

Instituto Municipal de Mercados de Barcelona 2014. Pla Estratègic dels Mercats de Barcelona 2015/2025. Barcelona: Institut Municipal de Mercats de Barcelona, Departament de Comunicació.

Jiménez, S. y Prats, Ll. 2006. "El turismo en Cataluña: evolución histórica y retos de futuro". PASOS: Revista de Turismo y Patrimonio Cultural, 4(2): 153-174.

Johns, C., Lyon, P., Stringer, R. y Umberger, W. 2017. "Changing urban consumer behaviour and the role of different retail outlets in the food industry of Fiji”. Asia-Pacific Development Journal, 24(1): 117-145.

Laajimi, A. y Albisu-Aguado, L.M. 1997. "El consumo de alimentos en España. Cambios y nuevas tendencias". Revista agroalimentaria, 3(5), 47-54.

Langreo, A. y Germán, L. 2018. "Transformaciones en el sistema alimentario y cambios de dieta en España durante el siglo XX". Historia Agraria, 74: 167-200.

Larrinaga-Rodríguez, C. 2019. "La hotelería turística de lujo en España en el primer tercio del siglo XX”. Ayer: Revista de Historia Contemporánea, 114(2): 65-94

Lasisi, T.T., Alola, A.A., Eluwole, K.K., Ozturen, A. y Alola, U.V. 2020. "The environmental sustainability effects of income, labour force, and tourism development in OECD countries". Environmental Science and Pollution Research, 27: 21231-21242.

Lasuén, J.R. y Baró, E. 2005. Sectors quinaris. Motor de desenvolupament de l’Àrea Metropolitana de Barcelona. Barcelona: Pla Estratègic Metropolità de Barcelona (PEMB).

Lavaur, L. 1987. "El siglo del Grand Tour (1715-1793)". Estudios Turísticos, 95: 73-110.

Lee, B.C. y Wicks, B. 2010. "Tourism technology training for destination marketing organisations (DMOs): Need-based content development”. Journal of Hospitality, Leisure, Sports and Tourism Education, 9(1): 39-52.

Lee, H., Lee, J., Chung, N. y Koo, C. 2018. "Tourists' happiness: are there smart tourism technology effects?". Asia Pacific Journal of Tourism Research, 23(5): 486-501.

López-Palomeque, F. 1994. "Actividad turística y espacio geográfico en el Umbral del Siglo XXI". Papers de Turisme, 14-15: 37-51.

Martín-Hernández, F. 2009. "La relación sociedad-naturaleza y el turismo. Reflexiones sobre el turismo de sol y playa”. Observatorium: Revista Electrónica de Geografía, 1(1): 105-123.

Martínez-Martínez, M., Fernández-Rodríguez, R. y Saco-Vázquez, M. 2008. Supermercados.com: Marketing para los Supermercados virtuales. Madrid: ESIC Editorial.

Medina, F.X. 2018. "Ir a comer al mercado. Aprovisionamiento, consumo y restauración en la transformación de dos modelos de promoción de los mercados urbanos (Barcelona y Madrid)". Revista Española de Sociología, 27(2): 267-280.

Medina, F.X. y Álvarez, M. 2007. "El lloc per on passa la vida... Els mercats i les demandes urbanes contemporànies (Barcelona-Buenos Aires)". Revista d'etnologia de Catalunya, 31: 59-69.

Martínez-Martínez, D. 2018. Estudio de las motivaciones finales de compra del consumidor: una perspectiva evolutiva. Universidad de Almería, Tesis Doctoral.

Medina-Liberty, A. 2009. "Evolución, sociedad y cultura". Ludus Vitalis, Revista de Filosofía de las Ciencias de la Vida, 17(32): 327-337.

Mili, S. 2005. "Transformaciones del consumo alimentario y su repercusión en el sistema agroalimentario". Estudios Agrosociales y Pesqueros, 205: 221-247.

Miller, M. 1993. "Mercats nou-centistes a Barcelona: una interpretació dels seus orígens i significat cultural". Revista de l'Alguer, 4(4): 93-106.

Molina, S. 2000. El Posturismo. De los centros turísticos Industriales a las ludópolis. México: Editorial Tesis Económicas Profesionales.

Montalvao, J y Van de Velde, P. 2020. COVID-19 and Food Security: Gendered Dimensions. Open Knowledge Repository. Policy Note. Washington D.C.: World Bank.

Montes-Gavilán, T.M. 2016. "Análisis de la accesibilidad en las sedes de turismo de eventos en Barcelona". ROTUR: Revista de Ocio y Turismo, 11: 50-64.

Moreno-Melgarejo, A., Sariego-López, I. y Ávila-Bercial, R. 2018. "La planificación y la gestión como herramientas de desarrollo de los destinos turísticos". Revista TURyDES: Turismo y Desarrollo, 11(25): 1-16. 
Navas-Ferrer, T. 2014. "La construcción simbólica de una capital. Planeamiento, imagen turística y desarrollo urbano en Barcelona a principios de siglo XX". Scripta Nova. Revista Electrónica de Geografía y Ciencias Sociales, XVIII, 493(13).

Observatori del Turisme a Barcelona 2020. Barcelona 2019. Informe de l'activitat turística. Barcelona: Observatori del Turisme a Barcelona.

Osorio-García, M. 2010. "Turismo masivo y alternativo. Distinciones de la sociedad moderna/posmoderna". Convergencia: Revista de Ciencias Sociales, 17(52): 235-260.

Palou-Rubio, S. 2006. "La Ciudad fingida. Representaciones y memorias de la Barcelona turística". PASOS. Revista de Turismo y Patrimonio Cultural, 4(1): 13-28.

Pallarès-Barberà, M. 2005. "La percepció d'optimalitat en el Pla Cerdà. El model p-median en disseny ortogonal L de l'Eixample de Barcelona". Treballs de la Societat Catalana de Geografía, 60: 223-253.

Pérez-Rodrigo, C., Gianzo-Citores, M., Hervás-Bárbara, G., Ruiz-Litago, F., Casis-Sáenz, L., Aranceta-Bartrina, J. y el Grupo Colaborativo de la Sociedad Española de Nutrición Comunitaria (SENC). 2020. "Cambios en los hábitos alimentarios durante el periodo de confinamiento por la pandemia COVID-19 en España”. Revista Española de Nutrición Comunitaria, 26(2):101-111.

Poelman, M.P., Van Lenthe, F.J., Scheider, S. y Kamphuis, C.B.M. 2020. "A smartphone app combining global positioning system data and ecological momentary assessment to track individual food environment exposure, food purchases, and food consumption: protocol for the Observational FoodTrack Study". JMIR Research Protocols, 9(1), e15283: 1-15.

Ponce-Vásquez, V. 2002. Contribución al desarrollo de un entorno seguro de m-commerce. Barcelona: Universitat Politècnica de Catalunya, Tesis Doctoral.

Puelles, M., Moreno, G. y Medina, F. 2019. Observatorio para la evolución del comercio electrónico de alimentación: avances y perspectivas 2019. Madrid: Universidad Complutense de Madrid, Asociación Española de Distribuidores, Autoservicios y Supermercados (ASEDAS).

Salinas-Arreortua, L. 2015. "Transformación de mercados municipales de Madrid. De espacio de consumo a espacio de esparcimiento". Revista INVI, 85(31): 179-201.

Serrano, J. 2020. "Plataformas de comercio electrónico e internacionalización empresarial". Información Comercial Española (ICE), Revista de Economía, 913: 167-185.

Steegmann, D. 2018." El nuevo sentido de un espacio colectivo: el mercado de la Boquería”. Quaderns d'arquitecturai urbanisme, 271: 75-86.

Suárez-Huerta, A 2012. "El Grand Tour: un viaje emprendido con la mirada de Ulises". ISIMU, 15: 253-279.

Tatje-Mir, M. 2018. "Los balnearios catalanes y el contexto peninsular. Historiografía e historia”. En J.M. Puigvert-Solà y N. Figueras-Capdevila (coord.). Balnearios, veraneo y literatura: agua y salud en la España contemporánea (pp. 25-72). Madrid: Marcial Pons, Ediciones Jurídicas y Sociales.

Urkía-Etxabe, J.M. 2004. "El esplendor de los balnearios". En Actas VIII Congreso de la Sociedad Española de Historia de las Ciencias y de las Técnicas (pp. 105-120). Logroño: Universidad de La Rioja.

Vallefin, L.A. 2018. "¿Inflando el Glovo?: Un análisis sobre los nuevos mecanismos de delivery y su abordaje en la jurisprudencia reciente”. Revista Derechos de Acción, 9(9): 403-426.

Webb, E.J., Campbell, D.T., Schwartz, R.D. y Sechrest, L. 1966. Unobtrusive measures: Nonreactive research in the social sciences. Chicago: Rand McNally.

Vidal-Casellas, D. y Crous-Costa, N. 2013. "Reseña de publicaciones: Barcelona, destinació turística. Un segle d'imatges i promoció pública". PASOS. Revista de Turismo y Patrimonio Cultural, 11(3), 163-165.

Zaar, M.H. y Pontes-da-Fonseca, M.A. 2019. "Turismo y consumo del espacio urbano en Barcelona. Análisis de la relación residente-turista en el barrio de La Barceloneta". Cuadernos de Turismo, 44, 487-514.

Zerva, K. 2020. "Tourism and COVID-19: Social and lateral marketing to the rescue". Communication Papers, 9(19): 144-153.

\section{Notas}

Idescat 2020. Población a 1 de enero. Por sexo y grupos de edad. https://bit.ly/39xdqwG (consultado 27/07/2020)

Mercado de La Boquería 2020. Inicio. https://bit.ly/2FIqi8A (consultado 20/08/2020)

Recibido:

$22 / 08 / 2020$

Reenviado:

$27 / 01 / 2021$

Aceptado:

$11 / 02 / 2021$

Sometido a evaluación por pares anónimos 